\title{
Образ ящерицы в фольклоре и обрядности хакасов (конец XIX - середина XX века)
}

\section{В. А. Бурнаков}

Институт археологии и этнографии СО РАН

Новосибирск, Россия

\section{Аннотация}

Впервые представлена характеристика образа ящерицы в традиционной культуре хакасов. Основу исследования составили фольклорные и этнографические источники. Используемые в работе фольклорные материалы отрывки из героических сказаний (алыптых нымахтар), сведения по обозначенной теме, собранные краеведом С. Е. Карачаковым, в авторском переводе на русский язык впервые вводятся в научный оборот. Дан анализ места и роли образа ящерицы в устном народном творчестве и обрядовой практике. В мифологическом сознании хакасов эта рептилия наделяется противоречивыми характеристиками, она устойчиво связывается с хтоническим миром и отождествляется с такими природными объектами и стихиями, как гора / скала, вода. Указанная мифологическая фигура осуществляла покровительствующие, защитные и лечебные функции по отношению к домашним животным и людям. Образ ящерицы играл важную роль в мифоритуальном комплексе хакасских шаманов, где она выступала в качестве одного из важнейших духов-помощников при мистериях. В связи с этим ее символическое изображение было широко представлено на шаманских бубнах.

Ключевые слова хакасы, культура, фольклор, ящерица, мифы, обряды, шаманизм

Для ичитирования

Бурнаков B. А. Образ ящерицы в фольклоре и обрядности хакасов (конец XIX - середина XX века) // Вестник НГУ. Серия: История, филология. 2019. Т. 18, № 5: Археология и этнография. С. 166-177. DOI 10.25205/18187919-2019-18-5-166-177

\section{The Image of a Lizard in Folklore and Rituals of the Khakass (Late $19^{\text {th }}-$ Mid 20 ${ }^{\text {th }}$ Century)}

\section{A. Burnakov}

Institute of Archaeology and Ethnography SB RAS Novosibirsk, Russian Federation

Abstract

Purpose. The aim of this work is to characterize the image of a lizard (kileski) in folklore and ritual practices of the Khakass people. Based on the goal, the following tasks were set: to analyze folklore and ethnographic information, to identify the key components of this mythological creature and to discover semantic links of the image with natural objects and elements. Chronologically, the framework covers late $19^{\text {th }}-$ mid $20^{\text {th }}$ Centuries. The choice of such time limits is due to the source base available on the research topic. Leading in the study is the principle of historicism, when any cultural phenomenon is considered in its development, taking into account specific situations. The research methodology is based on historical and ethnographic methods: remnants (relic) and semantic analysis.

Results. Our analysis has led us to the following conclusions: in the Khakass culture, the lizard played an important role. It is explained by the lizard being plentiful in the nature of Khakassia, and specifically because of its zoological specificity. In the mythological perception of this reptile, it had contradictory dual characteristics and caused ambiguous feelings. People designated the reptile as a creature living in two environments - earth and water, which is steadily associated with the lower world. At the same time, the image is often introduced into mythological and fairy-tale 
schemes involving other chthonic species, such as frogs and snakes. In the folklore of the Khakass people, the whole life support system of demonic characters of the lower world, which included farming and nutrition, was directly tied to these amphibians. A great importance was attached to the image of the frog and shamanic practice. The lizard had a direct relation both to the spirit-owner of the water - Sug eezi, and to the lord of the underworld - Erlik Khan. The designated specificity of the lizard allowed including it into the set of key spirits, whi were shaman's assistants. Shamans mediated between the world of the underground spirits and people: among shamanists, the worship of reptiles reached such a high level that the cult of the patron of sheep arose, the external data of which included the features of reptiles and amphibians.

Conclusion. The image of the lizard carried out patronizing, protective and therapeutic functions in relation not only to pets, but also to people. The importance of the lizard to the culture of the Khakass people was so great that its image was included into the traditional Khakass calendar "muchel". The latter was based on a twelve-year animal cycle. In the perception of the people, "kiles chili" - 'the year of the lizard' - was considered a good period.

Keywords

The Khakass, culture, folklore, lizard, myths, rites, shamanism

For citation

Burnakov V. A. The Image of a Lizard in Folklore and Rituals of the Khakass (Late $19^{\text {th }}-$ Mid $20^{\text {th }}$ Century). Vestnik NSU. Series: History and Philology, 2019, vol. 18, no. 5: Archaeology and Ethnography, p. 166-177. (in Russ.) DOI 10.25205/1818-7919-2019-18-5-166-177

\section{Введение}

В наши дни в связи с утратой многих черт традиционной культуры актуальным становится сохранение знаний о взаимодействии человека и природы в прошлом. При этом представления, связанные с животными, птицами и рыбами, становятся одними из ключевых объектов изучения этнографической науки.

В культуре хакасов особое место отводится животным и их образам. Символизм многих из них определялся зоологическими особенностями и утилитарной ценностью для человека. Наиболее значимые из животных наделялись высоким семиотическим статусом. Вместе с тем некоторые представители фауны, не имея сколько-нибудь явно выраженных биологических преимуществ перед остальными, а тем более какого-либо практического применения и хозяйственной пользы, все же были включены в обрядовую практику народа. К числу таковых относилась ящерица (хак. килескі).

Новизна работы определяется тем, что впервые на основе широкого круга фольклорных и этнографических сведений, в том числе ранее неизвестных, впервые будет проанализирован мировоззренческий комплекс хакасов, связанный с указанной рептилией. Целью работы является характеристика образа ящерицы в устном народном творчестве и обрядовой практике хакасов. Хронологические рамки исследования охватывают конец XIX - середину XX в. Выбор таких временных границ вызван состоянием источниковой базы по изучаемой теме. Ведущим в исследовании является принцип историзма, когда любое явление культуры рассматривается в развитии и с учетом конкретной ситуации. Методика исследования основана на историко-этнографических методах: пережитков (реликта) и семантического анализа.

\section{Результаты исследований и обсуждение}

Ящерица часто встречается в степях Хакасии. Факт ее широкой распространенности, а также зоологическая специфика, очевидно, способствовали тому, что ей придавалось немаловажное значение в мировоззрении и обрядности местного населения. В устном народном творчестве хакасов ящерица обладает неоднозначными характеристиками. Как известно из зоологии, вся система ее жизнеобеспечения связана с землей. Указанная рептилия ведет преимущественно наземный образ жизни, добывая себе пищу. Она использует норы, груды камней и скальные расщелины в качестве укрытия и жилища. В этих же местах производит свое потомство. Обозначенные реалии во многом предопределили отнесение ее к разряду хтонических существ. Причастность к подземному миру, а также некоторые внешние признаки форма головы, тонкое вытянутое тело, длинный хвост и чешуйчатость кожи, сближают ее 
со змеей. К последней черте сходства добавим, что в русском языке слово «ящерица», очевидно, восходит к корню ящер- в таком его семантическом значении, как «шероховатая кожа» [Фасмер, 1987. С. 572]. Близость обозначенных животных определена их принадлежностью к одному классу (пресмыкающихся), и, соответственно, сходством некоторых черт биологического поведения. Так, ящерица, подобно змее, любит греться на солнце. Обе рептилии являются хищниками и своих жертв проглатывают целиком, не имея возможности их разжевать. Названные факторы способствовали тому, что тюрки Южной Сибири эту рептилию порой называли оок / оох чылан - «мелкая / маленькая змея» [Дыренкова, 2012а. С. 303; Вербицкий, 1884. С. 108, 220; ХРС, 2006. С. 308, 1017].

В хакасском фольклоре всевозможные пресмыкающиеся и земноводные составляли значительную часть обитателей подземного пространства. При этом отдельные персонажи Нижнего мира использовали крупных ящериц в качестве транспортного средства [Бутанаев, Бутанаева, 2008. С. 37-38], а мелкие рептилии желтого цвета служили им плетью-камчой [Хан позырах..., 1969. С. 56]. Отметим и то, что жители подземного царства не только использовали обозначенных хтонических животных как средство передвижения и утилитарные предметы, но еще и употребляли их в пищу [Албынчі, 1951. С. 38; Ай Хуучын, 1958. С. 367]. В одном из эпических произведений герой описывает, как он попал в Нижний мир и неудачно пытался приобщиться к местной кухне:

«Пу одырган ирке-кинчеем,

Улуг типссе ит сызырган,

Улуг сараа мӥн урган.

“Эm ne", min, - чібізеге альın?"

Кӧрібіскем - кіліске парасхан

Килбейте пыс партыр.

"Кіліске дее полза, чіп

Кӧрченц ме min,

Пычахтаң кизіп, ахсыма

Тастабысхам,

Тайнап-тайнап, азыр полбаам,

Найла тади чох полван,

Ползар тӥкӥрібіскем", - тіпче»
«Эта сидящая красавица

В большом казане мясо сварила,

В большую чашу бульон налила.

“Мясо ли, - думаю, - взять и съесть?"

Посмотрел - бедняжка ящерица,

Разварившись, сварилась.

“Даже если ящерица, попробую

съесть”, - думая,

Разрезав ножом, в рот

Бросил,

Жевал-жевал - не смог проглотить,

Уж очень невкусной была,

На пол выплюнул [Ах Хан] говорит» ${ }^{1}$.

Обращает на себя внимание то, что в устном народном творчестве для жителей подземного пространства и других существ ящерица, наряду со змеей и лягушкой, является не только основной пищей, но и волшебным средством, способствующим сохранению и даже увеличению их жизненных сил. В богатырском сказании «Ах Хан на бело-буланом коне» одна из героинь аргументированно настаивает на том, чтобы земной богатырь все же отведал предлагаемую пищу:

«Кӥмӥс айахха толдыра

Узун килескілерні урып турвыстыр <...>

Кӥмӥс айахтаң ас-тамах чібезең,

Ил чиріне син чидіп,

Ирее-чобаг анда кӧп кӧріп,

Илбек кӥзін синің читпин,

Иртіп-ӧліп халарзың.

Тың аар, чобавлыг чирзер парыпчазыңџ»
«В серебряную чашу сполна

Длинных ящериц, наполнив, поставила < ..> Из серебряной чаши еду [если] не поешь, Достигнув земли [того] народа, Страданий-мучений там много увидишь, Великой силы тебе [тогда] не хватит, Перейдя-умерев, [там] останешься.

В слишком тяжелую, горестную землю [ты] отправляешься» ${ }^{2}$.

\footnotetext{
${ }^{1}$ [Чистобаева, 2015. С. 15-16].

2 [Ах Хан..., 2007. С. 231, 233]; перевод наш. - В. Б.
} 
Обращает внимание тот факт, что в эпических произведениях в образах ящериц нередко воплощаются души и жизненные силы самих демонических существ. Так, душа богатыря Нижнего мира Изил Молата представляется в образе двух ящериц:

«Ікі пастых ирем кӥрен ат,

Кізі тілінең тілленібіскен,

Кізі ӱнінең ӱнненібіскен:

- Алып аттың арванын хайда кӧрдің,

Тулбар аттың турванын хайда истің?

Хара сынның ӱстӥнде

Ікі килескінің пастарын

Син ӱзе тартыбысхханда,

Ол Изіл Молатнаң пістің

Арыг тыныбысты, чулабысты

Чох идібіскезің чізе»
«Двухголовый темно-бурый богатырский конь

Языком человека заговорил,

Голосом человека заголосил:

- Богатырского коня спину, где видел?

[O] богатырского коня стоянке, где слышал?

На вершине черного хребта

Двух ящериц головы

Ты, напрочь оторвав,

Это нашего Изил Молата

Чистую дух-душу

[Ты] уничтожил, ведь» ${ }^{3}$.

В богатырском сказании «Ай Мирген» злая сила в образе чудовищного коня вороной масти обладает душой в виде двухголовой ящерицы-змеи:

«Алтын Теек альип кізі

Оңнап-сынап кӧр килир.

Ікі пастыз килескі хурт -

Арыг тынынl, арых чулазы

Санмайы алтында чыл чӧр.

Чаачฺх сапхлабысхан,

Кіріс кіңребіскен -

Алтын Теек алып кізі

Килескі хуртты атхан,

Ікі пазын кизе атхан:

Ікі пастыз ӱлгер хара ат

Сай полып саалап халван,

Хум польи тоолап халван.

Алтын Теек алып кізі

Хара чирге сиип тӥскен〉
«Алтын Теек богатырь

Пристально осматривает [его].

О двух головах ящерица-змея

Чистое дыхание, [и] чистый дух [его]

Под висками извиваются.

Лук [готовый к бою] загремел,

Тетива [натянутая] запела -

Алтын Теек богатырь

[B] ящерицу-змею выстрелил

Две головы напрочь отстрелил:

О двух головах вороной конь

[B] гальку превратившись, осыпался,

В песок превратившись, рассыпался.

Алтын Теек богатырь

[К] черной земле притягиваясь, опустился» ${ }^{4}$.

Добавим, что такой отрицательный фольклорный женский персонаж, как Пора Нинці, в своих волосах носила ящериц и иных гадов. Очевидно, что это было не просто украшение. В традиционном мировоззрении хакасов волосы осмыслялись в качестве одного из мест локализации души человека и соотносились с его жизненными силами. Приведем соответствующий отрывок из эпоса:

«Хара пораттың ӱстӥнде,

Алтон сӥрмес иңніне чайыл парван.

Иліг сӥрмес иңніне чайыл парван,

Пора хан хызыь Пора Нинч̨і, Алтон сӥрместің пазында
«[На] темно-сером коне верхом,

[C] шестьюдесятью косичками, по плечам раскинувшимися.

[C] пятьюдесятью косичками, по плечам раскинувшимися.

Пора хана дочь Пора Нинчі,

На концах шестидесяти косичек

\footnotetext{
${ }^{3}$ [Курбижекова, 2011. С. 185]; перевод наш. - В. Б.

${ }^{4}$ [Ай Мирген..., 1959. С. 131].
} 
Пава, килескі прай ирелзіп Толвалызып парван〉
Лягушки, ящерицы все переплетясь, Накручены были» 5 .

В мифологических представлениях хакасов некоторые демонические персонажи не только обладали душой в виде пресмыкающихся или земноводных, но еще и были наделены соответствующими териоморфными чертами внешности. В героической эпике представлены следующие описания рассматриваемых существ:

«Саин Ханның чирі-чуртына Хара сӥрееліг кӧрінмес айна, Пазыныл, пахтырынарда килген.

Ікі пастыз, ирем кӥрең аттых Сині-кимі чох Изіл Молат.

Чылбырама чіг оорхалыг Чылтыр хара аттых Чеек Хан. Товыс хулас сунныг

Oй capaammblz

Изебі чох От Хан.

Аннаң андар удур-сооңдых

Килескі чиллектіг,

Чылан оорхалыг

Xара ой атmblz

Чылбазын Молат.

Чиллек хузурух

Чир тарт парван.

Чил хара аттыз

Пӧгімі чох Чірсі Мӧке.

Суруп хузурухтыз

Хара кӥрең аттығ

Ӧлбес Хара Хан.

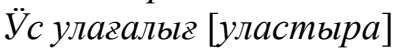

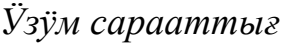

Ӱзумм Молат»
«[К] Саин Хану[в] землю-стойбище

Черное множество невидимых чертей,

Наступая [всем скопом], захватить явилось.

На двухголовом темно-буром богатырском коне

Могучий Изил Молат.

С гладким позвоночником

[Ездящий] на блестящем черном коне Чеек Хан.

Ростом в девять саженей

[Ездящий] на буланом коне

Могучий От Хан.

Туда-сюда, вперед-назад

С хвостом, как у ящерицы,

С позвоночником, как у змеи,

[Ездящий] на темно-буланом коне

Чылбазын Молат.

[Его] корень-Хвост

До земли протянулся.

[Ездящий] на диком (ветряном) черном коне

Могучий Чирси Мёке.

Со скрутившимся хвостом

[Ездящий] на темно-коричневом коне,

Неумирающий Хара Хан.

С тремя перекладными конями

[Ездящий] на быстром соловом коне

Ӱзӱм Молат» ${ }^{6}$.

В данном произведении при характеристике внешности богатырей-демонов Нижнего мира внимание заостряется на их зооморфности и прежде всего на такой части их тела, как хвост. В тексте он выделен следующими образными сравнениями: «хвост, как у ящерицы», «корень-хвост», «скрутившийся хвост». Акцент, сделанный в тексте на хвосте этого пресмыкающегося, вероятно, не случаен. Исключительная живучесть, обусловленная биологической способностью к автотомии / аутотомии - в случае опасности без всякого вреда для себя отбрасывать этот придаток части тела, является ключевым маркером рассматриваемой рептилии и ярко выделяет ее среди остальных животных. Вместе с тем эта удивительная зоологическая особенность в мифологическом сознании сближает ящерицу со змеей - существом, обладающим устойчивым символизмом возрождения. Известно, что ей присуща способность сбрасывать старую кожу. Указанный физиологический процесс в мифологическом мышлении воспринимался как ее символическая смерть и новое рождение. В рамках подобных представлений и ящерица, лишившись хвоста, его возрождает, и в целом - преображается сама.

\footnotetext{
${ }^{5}$ [Ай Мирген..., 1959. С. 131]; перевод наш. - В. Б.

${ }^{6}$ [Курбижекова, 2011. С. 96]; перевод наш. - В. Б.
} 
Рассматриваемая рептилия как существо хтоническое, а вместе с тем очень ловкое, юркое и вездесущее в традиционном сознании хакасов устойчиво ассоциировалась со зловредным духом айна. Данные представления нашли отражение в богатырских сказаниях. Так, в произведении «Ай Хуучын» этой рептилии дается соответствующая характеристика:

«Тӧреен ме, тӧребеен ме айналарың, Олар ӧтпеен чир човыл, $\ddot{У}$ ттіг наннаң ӱс ӧдіп, Тӧртінчізін тӧдір ӧдіп ирткеннер Андаг айналарыңны Типсебин полар ба хадарван мал!»
«Твои айна, едва родившись, В каждую дырку пролезут, Через ляжку трижды пройдут, В четвертый раз, выйдя обратно. Как не топтать скоту Таких твоих айна!» ${ }^{7}$.

В религиозно-мифологических представлениях хакасов все плохое, что могло произойти в жизни человека, объяснялось деструктивным влиянием духов айна. Поэтому совершено не случайно, что в фольклоре некоторые эпические герои призывают людей к уничтожению ящериц, видя в них злонамеренных тварей и потенциальную угрозу благополучию своему и собственного народа:

«Анда айланып, Хыс Хан

Хыйрылап, чоохтап турадыр:

"Оңдайлье чахсы кізілер, Олван-узахты халдырбаңуар, Ураa-аzас тудынын, Улуг чаава сызарзар!

Кирім сында тастых хыр, Килескі урвап ӧс партыр, Килескінің ӱрен-тӧлі халбазын, Тооза хырыңар, халых-чоныли! <..> Хан Мирген аны чапсып турадыр, Кирім сынны кӧріп турадыр:

Чир пӧзігі Кирім сыныл

Чон туу пас парван,

Хайаны хахсап турадырлар,

Тас алтында даа халдырбин, Тоозава харасханнар, Хызаан, хыймыхтаан хурт-хоос Халдырбааннар»
«Тогда Хыс-Хан, к ним обращаясь,

Громко наказ дала:

“Здоровые, достойные люди,

Детвору [тоже] не оставляйте!

Оружие-палки захватив,

На большую войну выходите!

На [хребте] Кирим-сын есть каменистый холм,

Уйма ящериц там расплодилась,

Пусть не останется племени-семени ящериц.

Всех, мой люд-народ, уничтожь! <...>

Хан Мирген этому удивился,

На [хребет] Кирим-сын смотрит:

Вершину земли - [хребет] Кирим-сын -

Народ собою сплошь закрыл,

Ищут в скалах,

Ничего под камнями не оставляют,

Всех уничтожить стараясь.

Ни прячущихся, ни движущихся насекомых

Они не оставили» ${ }^{8}$.

Способность ящерицы незаметно, неслышно и быстро, подобно злокозненным айна, перемещаться в пространстве нашла отражение и в обыденной речи хакасов. Указанная манера передвижения, представленная в языке, как правило, имеет отрицательную коннотацию. Так, например, в традиционном хакасском обществе мачеха нередко ругала падчерицу следующим выражением: «Килескі полып китенме, сомысхан полып сомсыйба» - «Не крадись, как ящерица, не крутись, как червяк» [Бутанаев, Бутанаева, 2008. С. 263, 282].

В устном народном творчестве хакасов каждая общность животных образовывала свое царство и имела правителя. В полной мере это относится и к ящерицам. В мифологических представлениях они, отстаивая свои интересы, нередко вступают в конфликты и даже боевые столкновения с земноводными и прочими:

\footnotetext{
${ }^{7}$ [Хакасский героический эпос..., 1997. С. 82-83].

${ }^{8}$ [Там же. С. 84-87].
} 
«Тастых хырдан килескі ин киледір,

Тагның идеене пага сых килген, Xатыз хыртылы

Урунызыли, хаабызыбылсханнар.

Изебі чох Хис Хан оларны таңнаан,

Пӧгімі чох Хилс Хан оларны чапсаан:

"Xурm-хоос maа

Ханны-пигні пілченьок полтыр", - тіп.

Хараавы тӥнде хыс чахсы

Xарап кӧр турадыр:

Хырдан килген килескі

Харавын аларта кӧр турадыр.

Илееде ирес-толвас парваннар.

Изебі чох Хис Хан кӧрзе,

Килескее пава сыдабинчададыр:

Паларльг састы кӧре,

Пава адыл турадыр,

Паларльв сасха кире

Паваны хостап салган килескі.

Килескі, хысхыр парып,

Сынга сых парыбысххан»
«С каменистого холма ползет ящерица,

К подножию горы поднялась лягушка,

На горном хребте

Столкнулись они, схватились.

Могучая Хыс-Хан изумлялась,

Бесстрашная Хыс-Хан удивлялась:

“Даже черви-твари

Хана-правителя знают, оказывается”, - сказала.

Достойная дева, в ночную темь

Всматриваясь, глядит:

Ящерица, спустившись с холма,

Злобно водит глазами.

Долго бились-сражались они.

Могучая Хыс-Хан видит:

Лягушка ящерицу одолеть не может -

В сторону тинистого болота

Лягушка отпрыгивает,

В тинистое болото

Лягушку ящерица загнала.

Покричав, ящерица

На гору поднялась» ${ }^{9}$.

В рассматриваемом эпосе, как и в целом в хакасском фольклоре, образ ящерицы устойчиво ассоциируется с горой / скалой. Данное представление является вполне закономерным ввиду того, что этот природный объект выступает излюбленным местообитанием указанных пресмыкающихся. Как уже отмечалось, они селятся и плодятся, в том числе, на крутых склонах ущелий и среди нагромождений крупных каменных глыб. Умеют ловко перемешаться по вертикальным скалам. Связь горы и ящерицы была столь тесна и крепка, что в религиозно-мифологическом сознании они нередко сливались в двуедином образе. Так, например, в шаманской поэзии в отношении почитаемых гор использовались соответствующие эпитеты: «о, вытянувшийся, подобно ящерице», «о, расстилающийся, подобно ящерице», «о, тасхыл, подобный головам девяти ящериц» [Катанов, 1907. С. 253-254]. Вместе с тем в верованиях хакасов ящерица естественным образом отождествляется и с самим «хозяином / хозяйкой горы» (maz ээзі) [Трояков, 1991. С. 316; Сагояков, 2010. С. 114]. В традиционных воззрениях этот могучий дух выступает в качестве незыблемого и законного владельца не только обозначенного природного сакрального объекта, но и сопредельной территории, включая всех зверей и птиц, на ней обитающих. Он является сакральным покровителем таежных животных и некоторых людей. При этом тад ээзі имеет способность приобретать как антропоморфный, так и зооморфный образы. В этой связи, хакасские религиозно-мифологические воззрения о ящерице обнаруживают общие семантические параллели с мифологическим образом Хозяйки Медной горы одноименной сказки П. П. Бажова. Согласно сюжету, она, будучи гением-хранительницей драгоценных пород и камней, предстает перед людьми в определенных случаях в виде прекрасной женщины, а иногда в образе ящерицы [Бажов, 2016].

В традиционных представлениях народа ящерица обладает прямой связью не только с горой, но и с водой - субстанцией, имеющей непосредственное отношение к Нижнему миру. По материалам Н. П. Дыренковой, хакасы и другие тюркские народы Саяно-Алтая называли ящерицу, а также змей и лягушек «духами, пришедшими от хозяина воды» - «суддаң килген» [Дыренкова, 2012б. С. 135, 183]. Данная мысль, вероятно, возникла не случайно. В немалой

\footnotetext{
${ }^{9}$ [Хакасский героический эпос..., 1997. С. 82-83].
} 
степени она была обусловлена зоологической реалией - ящерица хорошо плавает, а поэтому ей не чужда эта стихия. Среди хакасов поэтому получила распространение примета: если во сне человеку явится ящерица или упомянутые твари, то это предвещало неприятность со стороны суг ээзі - духа-хозяина воды [Дыренкова, 2012б. С. 183]. В ритуальных текстах она наряду с другими хтоническими животными выступает сакральной фигурой, которая препровождает некоторых существ к далеким мифическим морям - Хара талай и Capbz талай [Катанов, 1889. С. 113].

Символические свойства ящерицы, проявляемые в ловкости, проворности и вездесущести, закономерно предопределили то обстоятельство, что ее образ занял важное место в хакасском шаманизме. Эта рептилия была включена в круг духов-помощников шамана (тӧс'ов). Будучи существом по своей природе хтоническим, она наряду с другими пресмыкающимися и земноводными сопровождает кама в его мистических путешествиях в Нижний мир, в том числе и в глубоководные пространства [Потапов, 1981. С. 135; Дыренкова, 2012а. С. 303]. Ящерица помогала шаману в борьбе со злыми духами и конвоировала их на суд к правителю Нижнего мира - Эрлик-хану [Катанов, 1897. С. 30]. Столь важная роль, отводимая ящерице в шаманской практике, нашла отражение в самой атрибутике служителей культа, прежде всего в бубне. Изображение этой рептилии на нем было широко распространенным явлением в духовной культуре хакасов [Иванов, 1955. С. 209]. Рисунок наносился в нижней части бубна, соотносимой с подземным пространством. Ящерицу изображали одну либо парно - самец и самка (улуг / кічіz оох чылан (килескі)). При этом ее чаще выделяли черной либо зеленой краской [Катанов, 1897. С. 29-30, 35; 1907. С. 550-580; Катанов Н. (священник), 1889. С. 113-114; Яковлев, 1900. С. 57-58, 117; Тыжнов, 1902. С. 343; Потапов, 1981. С. 135; Дыренкова, 2012а. С. 303].

Хакасы верили в то, что ящерица наряду со змеей и лягушкой выступала в качестве ипостаси духа-покровителя овец Илгерге [Катанов, 1907. С. 592, 596]. Они были убеждены, что этот дух бдительно охраняет указанных домашних животных от злых духов [Катанов, 1897. C. 30]. Считалось, что он периодически напоминал посредством сновидений либо иных средств о необходимости принесения ему кровавой жертвы. В качестве таковой выступали холощеные бараны желтой и красной мастей. Обряд проводил шаман [Катанов, 1907. С. 556$557,592,596]$.

Указанный гений-покровитель не только патронировал мелкий рогатый скот, но и помогал людям избавиться от заболеваний рук и ног, а также глаз, хотя в некоторых случаях он и сам мог наслать недуги [Там же].

В фольклоре хакасов ящерица нередко осмысляется как положительный персонаж, предупреждающий человека об опасности. Краеведу С. Е. Карачакову со слов Ульяны Леонтьевны Амзараковой (1910 г. р., Кызлас аал) удалось записать на хакасском языке миф-быличку о том, как ящерица спасла человека от нападения змеи. Приведем ее в нашем переводе: «Однажды некий человек уснул в поле. [Рядом пробегала ящерица.] Она заметила, как к спящему человеку ползет крупная гадюка с намерением напасть на него. Ящерица с целью разбудить пробежалась по его лицу. [Однако] тот не просыпается. А змея все ближе подползает к нему. [Видя это], ящерица во второй раз прошлась по его лицу. Человек все также [крепко] спит. [A] змея [к этому времени уже так] близко подползла к нему, что едва не достает. Ящерица в третий раз пробежалась по лицу уснувшего. И только тогда человек проснулся. Сразу увидев гадюку, он тем, что первым попалось ему под руку, то ли камнем, то ли палкой тут же убил ее. С тех пор, говорят, змея и ящерица стали заклятыми врагами [Чылан..., 2004. C. 36].

Вера в сакральность ящерицы и ее охранительные функции, а также соответствующее местообитание и специфические внешние особенности, главным образом чешуйчатость кожи, возможно, послужили причиной того, что в культуре хакасов ее образ стал отождествляться еще и со священными буддийскими текстами - тантрами. Об этом, например, свидетельствует народная загадка: «Суzда сувдур пічік, тавда тавдыр пічік (палых хастырыzы, килескі)»- 
«На дне реки находится священное писание - сутра, на холме находится священное писание - тантра (чешуя рыбы и ящерица)» [Бутанаев, Бутанаева, 2008. С. 304, 322].

Значимость ящерицы для мифологии хакасов была столь высока, что ее образ оказался включенным в традиционный календарь хакасов «мӥчел». Его основу составлял двенадцатилетний животный цикл. При этом в восприятии народа «килескі чыллы» - «год ящерицы» считался хорошим временем [Бутанаев, 1996. С. 195].

\section{Заключение}

Представленные материалы позволяют сделать вывод о том, что в мифологии хакасов ящерице отводилось важное место. Данная реалия была обусловлена как широкой распространенностью этого живого существа в природе Хакасии, так и ее конкретными зоологическими особенностями. В традиционных представлениях народа она имела амбивалентную оценочную характеристику. Рептилия как существо, имеющее отношение к двум стихиям земли (горы) и воды, неизменно отождествлялась с Нижним миром. При этом ее образ неотделим от других хтонических животных - змеи и лягушки. В фольклоре отмечается, что ящерица выступает в качестве составного элемента системы хозяйствования и питания обитателей Нижнего мира. Вместе с тем в устном народном творчестве хакасов ящерицы организуются и формируют отдельные царства, которые осуществляют взаимодействие с земноводными и иными рептилиями.

Существенное место отводилось ящерице и в шаманизме. Она входила в состав основных духов-помощников, осуществлявших функцию медиатора между миром подземных духов и миром людей. Среди шаманистов почитание рептилии получило настолько широкое распространение, что возник культ покровителя овец. Одной из его ипостасей было данное пресмыкающееся. Ящерица распространяла защитные и лечебные функции не только на домашних животных, но и на людей. Некоторые биологические реалии, выражающиеся в особенностях экстерьера и антагонистических отношениях со змеями, вероятно, способствовали формированию положительной коннотации ящерицы как существа, извещающего человека об угрозах, своего рода защитницы людей. Возможно, это поспособствовало и включению ее образа в календарную систему хакасов.

\section{Список литературы}

Бажов П. П. Медной горы Хозяйка. Уральские сказы. М.: Речь, 2016. 144 с.

Бутанаев В. Я. Традиционная культура и быт хакасов. Абакан: Хак. кн. изд-во, 1996. 224 с.

Бутанаев В. Я., Бутанаева И. И. Мир хонгорского (хакасского) фольклора. Абакан: Хак. кн. изд-во, 2008. 376 с.

Вербицкий В. И. Словарь алтайского и аладагского наречий тюркского языка. Казань: Тип.лит. В. М. Ключникова, 1884. 494 с.

Дыренкова Н. П. Атрибуты шаманов у турецко-монгольских народов Сибири // Дыренкова Н. П. Тюрки Саяно-Алтая. Статьи и этнографические материалы. СПб.: МАЭ РАН, 2012a. C. 277-339.

Дыренкова Н. П. Вода, горы и лес по воззрениям турецких племен Алтайско-Саянского нагорья // Дыренкова Н. П. Тюрки Саяно-Алтая. Статьи и этнографические материалы. СПб.: МАЭ РАН, 2012б. С. 131-188.

Иванов С. В. К вопросу о значении изображений на старинных предметах культа у народов Саяно-Алтайского нагорья // Сб. МАЭ. М.; Л.: Наука, 1955. Т. 16. С. 165-264.

Катанов Н. (священник). Шаманский бубен и его значение // ЕЕВ. 1889. № 6. С. 112-114.

Катанов Н. Ф. Наречия урянхайцев (сойотов), абаканских татар и карагасов (образцы народной литературы тюркских племен, изданные В. В. Радловым). СПб., 1907. Т. 9.640 с. 
Катанов Н. Ф. Отчет о поездке, совершенной с 15 мая по 1 сент. 1896 г. в Минусинский округ Енисейской губернии. Казань: Типо-Литография Импер. Казан. ун-та, 1897. 104 с.

Потапов Л. П. Шаманский бубен качинцев как уникальный предмет этнографических коллекций // Материальная культура и мифология: Сб. МАЭ. Л.: Наука, 1981. Т. 36. С. 125137.

Сагояков Н. Н. Хакасские мифы. Абакан: Хак. кн. изд-во, 2010. 134 с.

Трояков П. А. Героический эпос хакасов и проблемы изучения. Абакан [б. и.], 1991. 326 с.

Тыжнов П. Призывание духов камами при нагорном жертвоприношении минусинских инородцев. Шаманство камов над больным. Тур или бубен. Арба. Шаманская одежда (конролыг тон). Шапка шамана (чалынмалалых пюрих) // ЕЕВ. 1902. № 11-12. С. 338-344.

Фасмер М. Этимологический словарь русского языка: В 4 т. М.: Прогресс, 1987. Т. 4. 864 с.

Хакасский героический эпос: Ай-Хуучин. Новосибирск: Наука, 1997. 479 с. (на хак. и рус. яз.)

ХРС - Хакасско-русский словарь. Новосибирск: Наука, 2006. 1114 с.

Чистобаева Н. С. Героический эпос хакасов: тематика и поэтика. Абакан: Бригантина, 2015. $170 \mathrm{c.}$

Яковлев Е. К. Этнографический обзор инородческого населения долины Южного Енисея и Объяснительный каталог Этнографического отдела музея. Описание Минусинского музея. Минусинск: Тип. В. И. Корнакова, 1900. Вып. 4. 212 с.

Ай Мирген. Героическое сказание, записанное от П. И. Сулекова. Абакан: Хак. кн. изд-во, 1959. 135 с. (на хак. яз.)

Ай Хуучын // Алтын Арығ. Алыптыг нымыхтар. Абакан: Хак. кн. изд-во, 1958. С. 318-420. (на хак. яз.)

Албынчі (алыптығ нымах) // Алыптығ нымахтар. Абакан: Хак. кн. изд-во, 1951. С. 13-98. (на хак. яз.)

Ах Хан на бело-буланом коне. Ах пора аттыг алып Ах Хан. Богатырское сказание, записанное от С. И. Шулбаева. Абакан: Хак. кн. изд-во, 2007. 276 с. (на хак. яз.)

Курбижекова А. В. Сибен Арыг (героическое сказание). Абакан: Хак. кн. изд-во, 2011. 324 с. (на хак. яз.)

Хан позырах аттығ Хан Мирген // Хан Мирген. Абакан: Красноярск. кн. изд-во, 1969. С. 9114. (на хак. яз.)

Чылан паза килескі // Карачаков С. Е. Чонымға ӧдізім айландырчам (Возвращаю свой долг). Абакан: Хак. кн. изд-во, 2004. С. 36.

\section{References}

Ai Khuuchyn [Ai Khuuchyn]. Altyn Aryg. Alyptyg nymakhtar [Altyn Aryg. Heroic legend]. Abakan, Khakass Book Publ., 1958, p. 318-420. (in Khakass)

Ai Mirgen. Geroicheskoe skazanie, zapisannoe ot P. I. Sulekova [Ai Mirgen. The Heroic Tale Written from P. I. Sulekov]. Abakan, Khakass Book Publ., 1958, 135 p. (in Khakass)

Akh Khan na belo-bulannom kone. Akh pora attyg alyp Akh Khan. Bogatyrskoe skazanie, zapisannoe ot S. I. Shulbaeva [Ah Khan on a White-Clad Horse. The Heroic Tale Written from S. I. Shulbaev]. Abakan, Khakass Book Publ., 2007, 276 p. (in Khakass)

Albynzhi. Khakasskoe geroicheskoe skazanie [Albynzhi. Khakass Heroic Legend]. Abakan, Khakass Book Publ., 1951, p. 13-98. (in Khakass)

Bazhov P. P. Mednoi gory khozyaka. Ural'skie skazy [Copper Mountain Mistress. Ural tales]. Moscow, Rech Publ., 1997, 144 p. (in Russ.)

Butanaev V. Ya. Traditsionnaya kul'tura i byt khakasov [Traditional Culture and Life of the Khakass]. Abakan, Khakass Book Publ., 1996, 224 p. (in Russ.)

Butanaev V. Ya., Butanaeva I. I. Mir khongorskogo (khakasskogo) fol'klora [World of Khongor (Khakass) Folklore]. Abakan, KhSU Publ., 2008, 376 p. (in Russ.) 
Chistobaeva N. S. Geroichekii epos khakasov: Tematika i poetika [The Heroic Epic of the Khakas: Themes and Poetics]. Abakan, Brigantina Publ., 2015, 170 p. (in Khakass and Russ.)

Chylan paza kileski [The Snake and Lizard]. In: Karachakov S. E. Chonyma odezem ailandarcham [I return my debt]. Abakan, Khakass Book Publ., 2004, p. 36. (in Khakass)

Dyrenkova N. P. Atributy shamanov u turetsko-mongol'skikh narodov Sibiri [Shaman Attributes in the Practices of the Turkish-Mongolian Peoples of Siberia]. In: Dyrenkova N. P. Tyurki Sayano-Altaya. Stat'i i etnograficheskie materialy [The Turks of Sayano-Altai. Articles and Ethnographic Materials]. St. Petersburg, MAE RAS Publ., 2012, p. 277-339. (in Russ.)

Dyrenkova N. P. Voda, gory i les po vozzreniyam turetskikh plemen Altaisko-Sayanskogo nagor'ya [Water, Mountains and Forest according to the Views of the Turkish Tribes of the Altai-Sayan Highlands]. In: Dyrenkova N. P. Tyurki Sayano-Altaya. Stat'i i etnograficheskie materialy [The Turks of Sayano-Altai. Articles and Ethnographic Materials]. St. Petersburg, MAE RAS Publ., 2012, p. 131-188. (in Russ.)

Fasmer M. Etimologicheskii slovar' russkogo yazyka [An Etymological Dictionary of the Russian Language]. In 4 vols. Moscow, Progress Publ., 1887, vol. 4, 864 p. (in Russ.)

Ivanov S. V. K voprosu o znachenii izobrazhenii na starinnykh predmetakh kul'ta u narodov Sayano-Altaiskogo nagor'ya [On the Meaning of the Symbols of Ancient Objects of Worship among the Peoples of the Sayan-Altai Highlands]. In: Sbornik Muzeya antropologii i etnografii [Collection of the Museum of Anthropology and Ethnography]. Moscow, Leningrad, AS USSR Publ., 1955, vol. 16, p. 165-264. (in Russ.)

Katanov N. (the priest). Shamanskii buben i ego znachenie [The Shaman Tambourine and Its Importance]. Eniseiskie eparkhial'nye vedomosti [The Yenisei Eparchial Bulletin], 1889, no. 6, p. 112-114. (in Russ.)

Katanov N. F. Narechiya uryankhaitsev (soiotov), abakanskikh tatar i karagasov (Obraztsy narodnoi literatury tyurkskikh plemen, izdannye V. V. Radlovym) [Dialects of the Uriyanghai (Soyots), Abakan Tatars and Karagas (Samples of Folk Literature of Turkic Tribes, published by V. V. Radlov)]. St. Petersburg, 1907, vol. 9, 640 p. (in Russ.)

Katanov N. F. Otchet o poezdke, sovershennoi s 15 maya po 1 sentebrya 1896 g. v Minusinskii okrug Enisseiskoi gubernii [Report on the Trip Dated May 15 to September 1, 1896 in the Minusinsk District of the Yenisei Province]. Kazan, Imperator Kazan Uni. Publ., 1897, 104 p. (in Russ.)

Khakasskii geroicheskii epos: Ai-Khuuchin [Khakass Heroic Epic: Ay-Huuchin]. Novosibirsk, Nauka, 1997, 479 p. (in Khakass and Russ.)

Khakassko-russkii slovar' [Khakass-Russian Dictionary]. Novosibirsk, Nauka, 2006, 1114 p. (in Russ.)

Khan pozyrakh attyg Khan Mirgen [Khan Mirgen on a Blood-Red Horse]. Khan Mirgen [Khan Mirgen]. Abakan, Krasnoyarsk Book Publ., 1969, p. 9-114. (in Khakass)

Kyrbizhekova A. V. Siben Aryg (geroicheskoe skazanie) [Siben Aryg (A Heroic Legend)]. Abakan, Khakass Book Publ., 2011, 324 p. (in Khakass)

Potapov L. P. Shamanskii buben kachintsev kak unikal'nyi predmet etnograficheskikh kollektsii [A Shaman Tambourine of the Kachints as a Unique Subject of Ethnographic Collections]. In: Matereial'naya kul'tura i mifologiya [Material Culture and Mythology]. Leningrad, 1981, p. 125-137. (Collection of the Museum of Anthropology and Ethnography. Vol. 36) (in Russ.)

Sagoyakov N. N. Khakasskie mify [Khakass myths]. Abakan, Khakass Book Publ., 2010, 134 p. (in Russ.)

Troyakov P. A. Geroicheskii epos khakasov i problemy izucheniya [The Heroic Epic of the Khakas and Its Studying]. Abakan, 1991, 326 p. (in Russ.)

Tyzhnov P. Prizyvanie dukhov kamami pri nagornom zhertvoprinishenii minusinskikh inorodtsev. Shamanstvo kamov nad bol'nym. Tyr ili buben. Arba. Shamanskaya odezhda. Shapka shamana [Summoning Spirits by Shamans at the Highland Sacrifice of Minusinsk Natives. Shamanism over the Sick. A Tyur or Tambourine. Arba. Shaman Clothes. Shaman's Cap]. Eniseiskie 
eparkhial'nye vedomosti [The Yenisei Eparchial Bulletin], 1902, no. 11-12, p. 338-344. (in Russ.)

Verbitsky I. I. Slovar' altaiskogoi aladagskogo narechii tyurkskogo yazyka [Dictionary of the Altai and Aladagan Dialects of the Turkic Language]. Kazan', V. M. Klyuchnokov Publ., 1884, 494 p. (in Russ.)

Yakovlev E. K. Etnograficheskii obzor inorodcheskogo naseleniya doliny Yuzhnogo Eniseya i ob'yasnitelnyi katalog etnograficheskogo otdela muzeya. Opisanie Minusinskogo muzeya [Ethnographic Survey of the Alien Population of the Valley of the Southern Yenisei and the Explanatory Catalog of the Ethnographic Department of the Museum. Description of the Minusinsk Museum]. Minusinsk, V. I. Kornakov Publ., 1900, iss. 4, 212 p. (in Russ.)

Материал поступил в редколлегию Received 14.01.2019

\section{Сведения об авторе}

Бурнаков Венарий Алексеевич, кандидат исторических наук, старший научный сотрудник Института археологии и этнографии СО РАН (пр. Академика Лаврентьева, 17, Новосибирск, 630090, Россия)

venariy@ngs.ru

\section{Information about Author}

Venariy A. Burnakov, Candidate of Historical Sciences, Senior Researcher at the Institute of Archaeology and Ethnography SB RAS (17 Academician Lavrentiev Ave., Novosibirsk, 630090, Russian Federation)

venariy@ngs.ru 